\title{
Research on the Characteristic Model and Practice of China's Urban Grassroots Social Governance Model
}

\author{
Mingyang Ruan \\ Kunming University \\ Kunming, China 650214
}

\begin{abstract}
China's urban grassroots social governance model has undergone a profound transformation since the 1990s. It has evolved from a unit system to a community system, going through three forms of community service, community construction, and community governance, and it has gradually formed a distinctive model of "linkages of four social forces", namely, an interactive system of community, social organizations, social workers and community volunteers, led by the government.
\end{abstract}

Keywords-grassroots social governance; community governance; "linkages of four social forces"

\section{INTRODUCTION}

With the deepening of China's social transformation, the grassroots social governance model is facing profound changes. The result of the transformation is the gradual deconstruction of the traditional "unit system" society and the silent rise of the emerging "community" system. Judging from the political practice of the grassroots political power in China, the transformation of the grassroots social governance mode not only needs to break the original relationship between the state and society, but also needs a set of operational mechanisms to balance the interests of all parties. These all require the community as a platform to build a new community governance system based on the integration of social resources. In the process of constructing a new social governance system, it presents a diversified pattern of community governance subjects, including community neighborhood committees, social organizations, community volunteers, community property management organizations, the owners committee, and community residents. Community multi-stakeholders participate in community governance, provide community services and participate in community building through their own efforts to promote community progress, which meet the needs of different interest groups of the community, and promote the establishment of the "linkages of community multi-subjects" mechanism.

\section{THE TRANSFORMATION OF THE GRASSROOTS SOCIAL MANAGEMENT SYSTEM}

In general, the management system of China's urban social grassroots construction has experienced a shift from "unit system" to "community system", while community system has experienced gradual evolution and sublimation of the three stages, including "community service", "community construction" and "community governance".

\section{A. Community Services}

The evolution originated from the separation of government and enterprise in the 1980s and 1990s. The social service and social control functions of state-owned enterprises and collective enterprises gradually began to disappear. A large number of social problems associated with individuals began to return to the residents' places. In view of this, the Ministry of Civil Affairs began to implement "community services" in the mid-1980s and first proposed the concept of "community". At the Conference on Civil Affairs in Dalian in 1987, the Ministry of Civil Affairs first proposed the concept of community service, positioning it as "under the leadership of the government, launching and organizing members of the community to carry out mutual social service activities to solve the local social problems". In September of the same year, the Ministry of Civil Affairs held a meeting in Wuhan to define community service as "a variety of social welfare and social services provided by the community for people's material and spiritual life", requiring community services throughout the country. However, at the time, the Ministry of Civil Affairs' understanding of "community service" still remained at the stage of mutual assistance service and commercial service. It did not recognize the importance of welfare and public welfare social services, nor did it involve institutional issues of community construction and community governance.

\section{B. Community Building}

The community services, to a certain extent, have met the needs of residents, but it is difficult to cover the social functions that the government wishes the urban grassroots community undertake. Therefore, the Ministry of Civil Affairs introduced the concept of "community building" in 1991. In 1998, system reform scheme determined that the Ministry of Civil Affairs established a grassroots political power and community construction department on the basis of the original grassroots political power construction department. In November 2000, the General Office of the State Council forwarded the "Opinions on Promoting the Construction of Urban Communities in the Whole Country" of the Ministry of Civil Affairs. As a result, community construction was launched throughout the country and widespread quickly. "Two-level government, three-grade 
management, and the four levels network" were formed in this process, and the focus of urban management moved down, strengthening the "Shanghai model" of the administrative power of the sub-district office. The "Shenyang Model" of autonomous organizations such as the representatives of community members, the Community Consultative Committee, and Community management committee were set up between the street and the neighborhood committee. Besides, the "Jianghan Model" combining the administrative control mechanism of community autonomy and the mechanism of community autonomy was emphasized on the basis of the "Shenyang Model". These models all reflect that the focus of urban management moved down, giving the sub-district office the "quasi-government" power of community management, and turning the past urban planning system of "taking leadermember relation as the principal, and regional coordination and cooperation complementary" into the system of "regional coordination and cooperation as the principal, integration of leader-member relation and regional coordination and cooperation". At the same time, some residents' self-government explorations have also been carried out. These practices of "community construction" have fundamentally changed the physical environment of urban community greening, sanitation, cultural facilities, etc., making people's living environment have an external form of "community". It has solved the realistic difficulties of some vulnerable groups in the community. However, the "community-building" system is still only a re-adjustment of the administrative powers and functions in the government's administrative system. It does not solve the disadvantages of governments in the social field such as "regardless of government and community", "confusion of government and community", and "replacing the community by the government". In the community building, people can't see the society for the government, and the enthusiasm of various subjects in the community is not mobilized. It is impossible to build the community into a "community of living", so the community is still the "unit" of government administrative management. In the past two years, the "grid management" model that emphasizes the solution of social problems and the stability of grassroots society in urban communities, and emphasizes that the strong control should be linked to the assessment of residents committee is the typical representative of community administration. For the situation that community administration is strengthened and autonomy is insufficient in community construction, it can be explained by the strip traditional administrative management system of "one thousand thread a needle" and the dilemma that the first-line community staff feel that the neighborhood committee has too many administrative affairs and insufficient capacity to organize residents' autonomy effectively and provide high-level residents' services.

\section{Community Governance}

After the national demand for urban community construction at the end of 2000, some community workers felt that the community construction system has an urgent need for reform, but have no idea of the community work. In view of this, in 2003, the Shanghai Civil Affairs Bureau held a "Seminar on community building and social work" at East China University of Science and Technology. The conference proposed that community construction should introduce professional social workers and social work institutions, and social organizations should be established as soon as possible. A "linkage" effect of the institutional framework for social workers entering the community and an "interactive" mechanism with the community, social work, and social workers should be created. On the basis of this, Shanghai Municipal Civil Affairs Department put forward the concept of "linkages of three social forces" including "community", "social worker", and "association".

In 2004, and it also formed the working thought of "taking the community as the working platform, taking social workers as the team gripper, taking the society as the organizational carrier, and sharing out the work and cooperating with one another". With the deepening understanding of community governance, the civil affairs department changed the "three social interaction" to the "linkages of three social forces", putting more emphasis on the connection and coordination among the three.

Subsequently, the Third Plenary Session of the 18th CPC Central Committee made a strategic deployment of "innovating social governance system" and replaced the previous "social management" with "social governance", which means giving the society subjectivity and emphasizing that various forces are also the main body of social governance, not just the complementary strength of government work. Under this background, "linkages of three social forces", as a new framework for social governance and an effective mechanism for community governance innovation, has been highly valued by the government, especially the civil affairs department, and has been widely spread in practice. "Linkages of three social forces" is based on the government purchase of services, the community provides a practical platform, social organizations serve as a service carrier, and social workers as professional support, and its ultimate service goal is to meet the needs of residents. It is a new social governance model, a social service supply method and a new social mobilization mechanism that after social organizations introduce external resources, social workers provide specialized and targeted services, and resolve conflicts in the community as well as realize the supply of diverse services in the community. The essence is that the government and social organizations fully cooperate with each other and social organizations lead community residents to participate in community-based governance, and provide personalized and professional services according to the needs of residents under the supervision of the government.

Since 2015, with the acceleration of the urbanization process, in the specific practice, the community governance framework with the "linkages of three social forces" as the mainstream has a new extension. In the developed regions, the formulation of "linkages of four social forces" has emerged. On October 9, 2015, Xinhua News Agency published a commentary titled "Core Leading the linkages of four social forces" Having Demonstrative Value, introducing the advanced model of Pingshan district, Shenzhen, pointing 
out that the "linkages of four social forces" in Pingshan is the modernization exploration of grass-roots governance system with the primary party organization as the core and the participation of community, social organizations, social workers and social forces.

\section{DeVElopment StATUS OF CHINESE COMMUNITY GOVERNANCE MODEL}

At the present stage, the practice and exploration of community governance across China all are concentrated on the selection of "linkages of three social forces" and "linkages of four social forces" mode. The operational mechanisms of community governance in different regions are not the same, and how to choose the right development model and strategy according to the regional situation is the key. In the academic world, scholars are more likely to take the "linkages of three social forces" mechanism as a new approach to explore community governance as well as a new measure of civil affairs innovation and social governance promotion. In terms of practical work, the "linkage" of each region is in the preliminary exploration stage, and the implementation areas are limited. How to find the governance path in practice is related to the governance effect of each region. Considering the various entities involved in community governance as part of a social system, summarizing the role of all parties involved in the community management in the "linkages of four social forces", finding out the problems, and propose suggestions to improve the system efficiency from different angles and improving the "linkages of four social forces" operation mode can promote community governance better.

\section{A. "Shanghai Mode"}

Judging from the powers of the parties in the community governance, Shanghai is a "strong society + strong government" model.

Since the birth of the concept of "community system", a large number of foreign and local social organizations (13,355 up to April, 2016), supported by the strong community of the government, developed into huge social worker teams and a volunteer teams (among them, the number of social workers was 14,000, and the number of registered volunteers reached more than two million in 2016. Besides, the government agency of the Shanghai Municipal Social Work Committee, which is a government agency specializing in social organizations and social workers, made Shanghai become the pioneer and frontier of China's civil society. Since the 1980s and 1990s, social organizations have taken the lead in development. The entry of a large number of foreign NGOs has rapidly expanded the scale of Shanghai's public welfare organizations, trained a large number of social workers, and realized the localization of social organizations and social workers. After 2000, The Shanghai Social Work Committee was established and it provided organizational security and policy support for communities, social organizations, social workers and volunteers. Seeing from the timeline, Shanghai is taking a leading place in China in professional and multi-disciplinary social work services, such as "community detoxification" at the end of the 20th century. Since 2005, characteristic modes such as "anti-domestic violence center", "community temporary family", "home care for the elderly", "Community Theater", "urban integration" of migrant population and so on have launched. In recent years, "community governance" model in Shanghai has begun to seek a refined and professional development path, echoing the needs of comprehensive management and stability, and community services have turned to minority groups. Carrying out related activities as well as linking with legal resources and social work resources helps ethnic groups to integrate into urban life, promote national unity and the development of ethnic and social work, which open up new paths for grassroots community governance and maintain social stability and solidarity. In particular, "linkage of two social forces" (social workers and volunteers) mechanism in Shanghai takes community construction as a platform, and active participation of social organizations as the way to give full play to the leading role of social workers and volunteers. Creating a model in which social workers lead volunteers and volunteers assist social workers to serve the community, so as to achieve the linkage of social workers and volunteers, and mutual benefit. In this mode, social workers play a core role, and volunteers support the platform as a basic resource. Social workers recruit volunteers, conduct training and supervision according to the requirements of the service projects.

From the perspective of the "community governance" in Shanghai, it has gone through the process from focusing on service people, social workers and volunteers helping the community development together to focusing on the needs of residents. Finally, it emphasizes the roles of community, social organization and social workers, and builds a platform for community service. Three kinds of social forces go hand in hand to build a more complete interactive platform for community governance.

\section{B. "Beijing Mode"}

The grassroots social management in Beijing is affected by the inertia of the "unit system" and forms the linkage model of "government-leading + operation of social worker office". At the end of the 1990s, with the demise of the unit system, the world of civic life returned to the community, forming a community management system centered on the "neighborhood committee", "home committee" and "mechanism courtyard". The basic idea of the management model is "all-round intervention and in-depth supervision", and finally, the famous supervision mechanism of "Chaoyang Aunts" is established. After 2000, with the establishment of the CPC Beijing Municipal Social Work Committee, the government began to fully participate in community construction and management. In October 2009, Beijing took digital city management as its starting point, and achieved remarkable achievements in the fields of community greening, safety, health and cultural construction, and formed a complete working model. The most prominent representative of this is "full-mode social service system in Chaoyang district". The so-called "full model"is the social service management system including 10 sectors such as 
emergency management, urban environment, comprehensive management and maintaining stability, safety production, social undertakings, social security, social services, economic dynamics, law and justice, and the work of Party building, 118 large categories, 577 categories, and 3575 subcategories. From the perspective of linkage among the parties, "Chaoyang mode" in Beijing is, firstly, establishing a linkage service mechanism, secondly, determining the functional positioning of the linkage parties, thirdly, establishing a linkage system and platform, and finally providing all aspects of protection. The four systems have distinctive Beijing characteristics, including the joint conference system, the information communication system, the service joint system, and the demand feedback system. In order to ensure the effective operation of the "linkages of three social forces", four types of security are also proposed to support the development of various linkage entities in the community from all aspects, namely, organization, policy, profession and talent protection. From the "Chaoyang mode", community governance model in Beijing is undoubtedly a peak representative of "community administration".

After 2010, with the normalization of the government's "purchase of services" behavior, a large number of "social work offices" with college teachers and students as the main working groups began to emerge. The volunteer team formed after the 2008 Olympic Games also provided a mass base for community work. The formation of these organizations and manpower conditions have comprehensively raised the level of community governance in Beijing in the aspects of the scientificity of community work methods, the advancement of ideas, and the depth of services.

In recent years, there are new developments of community governance model in Beijing, showing the development trend of professionalism, localization and "Internet +". For example, in the "Community soldier" mode of Huilongguan Community, the community affairs are entrusted to "veterans", and the veterans undertake the "package" community management project such as urban management, community security, and city appearance; and for another example, the Beijing Yanshan Party Working Committee drives community governance with party building and creates a number of advanced brands of community services, such as: "Cherishes the time to encourage" Morning speak of young civil servants; "threefive" raising the flag, I serve first; "tiny" work method, building a bridge; In addition, since 2014, "Guoan Community" has started implementing the commercial "Smart Community" based on the concept and technology of "Community Internet + and Off-line O2O". At present, more than 100 offline service outlets have been developed in Beijing. The outlets mainly provide community residents with basic community property, community life, community shopping, community interaction, community government affairs and community information services to create convenient, fast and high quality online and offline life experiences.

Generally speaking, the leader of the "Beijing model" is the government. The government's power can intervene in the residents' lives comprehensively and deeply. In recent years, as a result of "delegating power" and "purchasing" services, social work offices, various NGOs and volunteers have been developed vigorously; community governance is on the road to professional development.

\section{C. "Shenzhen Mode"}

As a pioneer of reform and opening up, Shenzhen has a high level of urbanization and modernization. Therefore, the community governance model of Shenzhen has centered on the work picture of "urbanization" and "community", and has constructed a model of "multiple co-governance of government security + market mechanism" with community comprehensive service organization as the core. In the early 1990s, Luohu District of Shenzhen became a pilot project of "Construction of a national safe and civilized community". Its basic experience model is characterized by: under the guidance of the unified planning of the government, it introduced the market mechanism in some community service areas that could realize market operation and took the construction of a safe and civilized community as a starting point, broke up the whole into parts, decentralized management as well as combined the social functions of the neighborhood committee with the commercial operation of the property management company organically to form a highly market-oriented model of community building and management. This is the famous "Luohu Pattern". After 2000, with the transformation of government functions, the wide spread of the social work concept of "helping others is a kind of self-help" in Hong Kong and the improvement of financial capacity in Shenzhen, the community governance model has undergone profound changes. Shenzhen has pioneered the operating methods of "one-stop" service in the community, and put forward the "four-dimensional conception" of institutionalized community construction: First, decentralization including "Separation of committee and station", "separation of residence and station", "one station for multiple residences" and "separation of residence and enterprise"; Second, volunteer and specialized service meaning creating a "duplex" team linked by "volunteer" and "social workers", which was later absorbed and practiced by Shanghai; Third, the daily and universal participation of residents; Fourth, government simplification, simplifying from "city-district-street-community" to "city-community".

After 2005, with the expansion of social workers, the emergence of social workers and the growing diversified needs of community residents, community-based service organizations relying on and linking with communities became popular, and were quickly implemented throughout the Pearl River Delta. After 2010, the development of social work in Shenzhen tends to be professional and high-qualified. Relying on the resources of college think tanks, various local social service centers have been established. The service groups cover children, adolescents, women, the elderly, the disabled, and the builders in Shenzhen, special hardship groups, etc.; the services include cultural and sports activities, community day care, re-employment training, coordination of family issues, schools from 4:30 p.m., etc. Based on this, in 2014, Shenzhen was awarded the title of "national 
innovation demonstration area of community governance and service" by the Ministry of Civil Affairs.

In 2015, Shenzhen issued the "Guidance on the Reform of Grassroots Management System", which summarized the community governance model in Shenzhen as "the multigovernance model of government and market". The so-called "multi-governance" refers to building a new mechanism that takes the comprehensive party committee of the community as the core, the self-governance of the neighborhood committee as the foundation, the community work station as the service platform for government affairs management, and all kinds of community bodies participate together, forming a new pattern of grassroots governance under the leadership of the party committee, and with the responsibility of the government, social coordination, public participation and the guarantee of the rule of law. Besides, it refers to the clear definition of respective roles and specific functions of seven important forces in the community including community integrated party organizations, community neighborhood committees, community workstations, community service centers, community social organizations, committees of the owners and community service agencies, as well as the departments stationed in the community and making a clear assignment distribution to create synergy.

In general, the "Shenzhen Model" has made a useful attempt in the institutional innovation of community governance. Its core idea is the multi-integrated management of "government departments + market power + third sector". Moreover, it found the new opportunity in the exploration of combination of reduction, commercialization and public welfare.

\section{CONCLUSION}

In the specific practice of China's governance in the past urban community governance, this model presents two paths: First, led by the neighborhood committee of the community, training community volunteer teams through the "internal personnel allocation and external guidance mechanism" and establishing the community grid management system; Second, guided by social organizations and after introducing external resources and integrate social forces, social workers provide professional and targeted services to resolve conflicts and provide services in the community. The two paths have their own origins, which represent the faces of the "government" and the "third sector". The innovative practice of "linkage of four social forces", the frontier of social governance at the grass-roots level of Chinese cities, is centered on the integration of two faces, trying to explore the "third" road so as to realize the concretization and realism of social governance: sinking to the daily life, and "landing" to the grassroots society.

At present, in China's urban grass-roots social governance practices, new characteristic models have emerged. The most typical ones are: "Shanghai model", which is reflected in the linkage model of "strong government + strong social workers" integrating social workers, volunteers and social organizations with the government as the main body; the "Beijing model", which is expressed as "government purchase + social work office", emphasizing that the government purchase incubation and cultivate social organizations, so as to promote the effectiveness of urban community governance; "Shenzhen model", which is characterized by the model of "multinational governance of government guarantee + market mechanism", paying more attention to the role of the government in regulating market mechanisms, and introducing market mechanisms in urban community governance to form a pluralistic co-governance model.

In general, the "linkage of four social forces" model is maturing, it established an urban community comprehensive public service center with the government as the main body and realize the "separation of government and society" between the center and the street with the center as the platform, the government purchases services, the interaction of social organization and community neighborhood committees as a carrier, the professional support of social workers. The community volunteers participate in the community and ultimately meet the needs of community residents. At the same time, by linking community with social organizations, and social workers with community volunteers in an organic way, social organizations and social workers giving full play to their professional and scientific advantages, as well as community and community volunteers demonstrating their mobilization and familiarity, finally the development pattern of social work that is "led in a unified way by the Party Committee of the Communist Party of China, driven by government, operated by the social organizations, and extensively participated by the public" is formed, and a community-based comprehensive service platform with "classification", "process", "strong interaction", "conciliation" and "specialization" is established.

\section{REFERENCES}

[1] Dong Xiu. Research on the Community Governance Model in Which the Non-governmental Organization "NGO" in Shenzhen Participate - Taking Shenzhen Social Work Organization as an Example [D] Sun Yat-sen University, 2010

[2] Sanders. "Community Theory" [M]. Liming Cultural Inc., 1982.

[3] Feng Na. Research on Urban Community Governance in ChinaTaking Community Governance in Chengdu as an Example[J] The Journal of Yunnan Administration College, 2012(03).

[4] Pan Xiaojuan. Research on China's Grassroots Social ReconstructionCommunity Governance [M]. China Legal Publishing House, 2004.

[5] Xiang Deping, Shen Kejun. Reconstruction of Community Autonomy and Grassroots Social Governance Model [J]. Gansu Social Sciences, 2013 (02).

[6] Wei Na. China's Urban Community Governance Model: Development Evolution and Institutional Innovation [J]. Journal of Renmin University of China, 2003 (1).

[7] Li Renli. How does "Linkages of Three Social Forces" in Beijing Do [N] China Community Newspaper, 2015.01.30.

[8] Li Sixian. Exploration of "Linkages of Three Social Forces" on a New Model of Social Governance [J]. Kunming Daily, 2015.07.26 (1).

[9] Zhan Jingxian,Pan Dejin,Song Yu,Wei Hongliang.Practice and Reflection on the Community Management Model of " Integration of Three Social Forces"_- Taking the Exploration of Chaoyang District in Beijing as an Example [J].Reform \& Openning, 2015(05). 
[10] Zhu Qinhao. Strengthening the Innovative Social Governance of "Linkages of Three Social Forces" [N]. New theory, Decision-making Reference, 2015.21.

[11] Wang Zimo. Research on the "Three Social Associations" Mechanism Promoting the Development of Social Work in Guangzhou Urban Communities [D], 2014.05.

[12] Zhai Lin. Analysis on the "Linkages of Three Social Forces" Mechanism in Community Governance-Taking the Practice of Taizhou, Jiangsu as an Example [D] Nanjing University, 2013. 